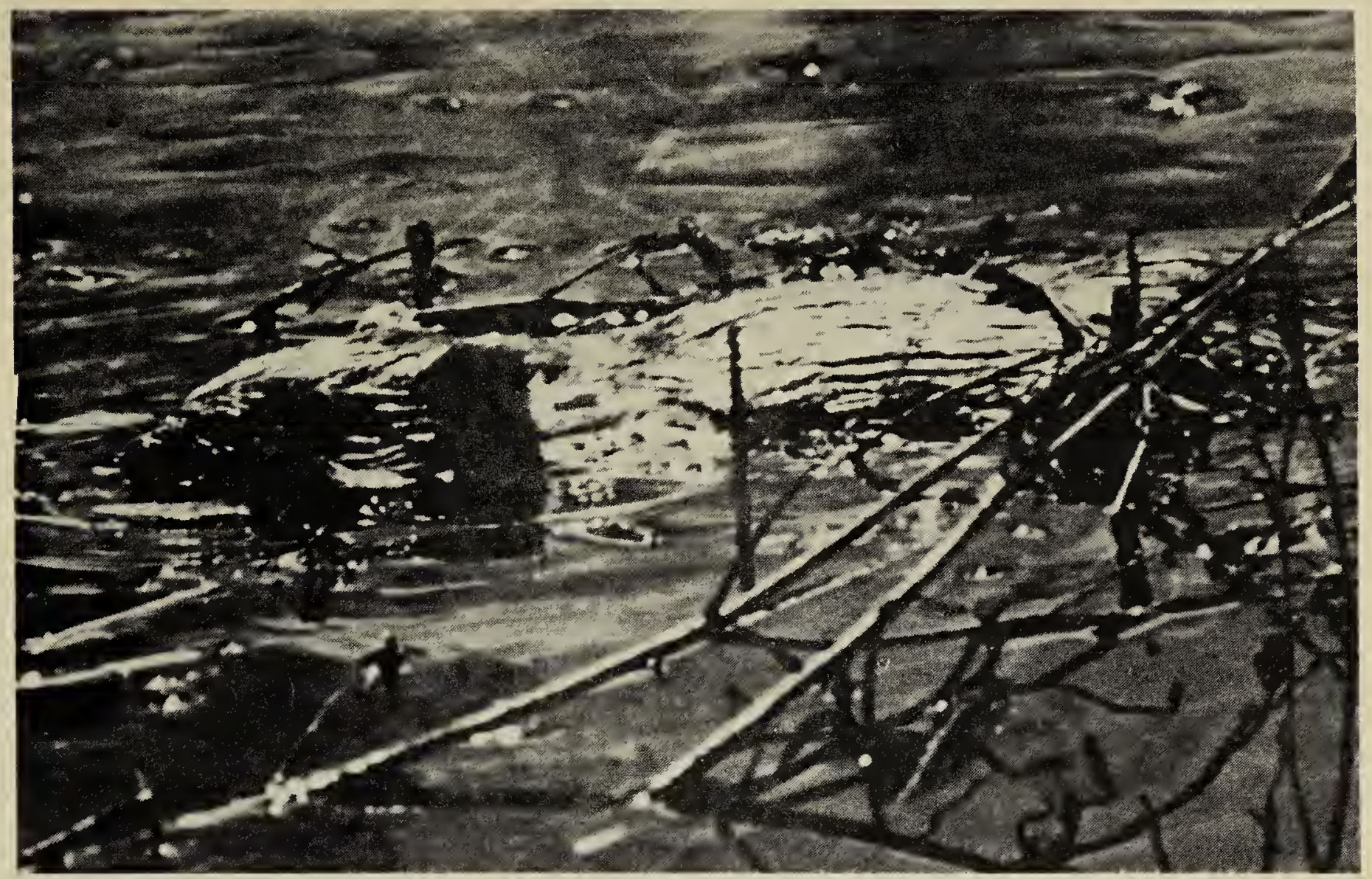

Beaver

F.A. Switzer

\section{BEAVER SWIMS UP WATERFALL}

\section{COLLEEN GERWING, 3 - 510 11th Street East, Saskatoon, Saskatchewan. S7N 0G2}

At dusk on a day in the third weekend in May I was paddling alone on a lake in northern Saskatchewan. I approached a break in a Beaver dam and saw what looked like a Muskrat hydroplaning towards me. I was surprised at how close it came to the canoe, but it gave me a chance to see that it was a fish that had come up the little waterfalls created by the break. The break in the dam was about 15 in. across; water dropped about 20 in. into a pool below. This pool was held by a rough secondary dam which fed a moderately moving creek. I halted by the dam and watched another fish try five times before making it from stream to lake.

For a long time nothing happened, until a Great Blue Heron hurtled into a nearby spruce. I was distracted from the heron by a variety of ducks and a small Beaver which seemed to resent my presence. They all disappeared and I focused back on the heron. Again the Beaver came nearby but was quickly frightened off by the slightest movement. Just as the heron flew away I heard some gurgling and plopping at the little falls. I looked there just in time to see this same Beaver swimming upstream just as the fish had done. It had to struggle, but made it up the first time, then swam away in a hurry, head above water.

I have never heard of Beaver travelling up very strong currents or falls, and I was very surprised that this one had taken the chance when it was aware of my close presence. At the end of the dam there was a short well-used overland route it could have taken, much farther away from me.

Beaver are timid in the wild while also displaying curiosity and mischief. Perhaps this yearling had just that extra sense of adventure. 